\title{
Towards Meaningful Decolonisation: The Role of Engaged Anthropology and Academic Coaching in the Decolonisation Project in South African Higher Education
}

\author{
Theodore Petrus \\ Department of Anthropology, University of the Free State, Bloemfontein, South Africa \\ Email: petrusts@ufs.ac.za
}

How to cite this paper: Petrus, T. (2021). Towards Meaningful Decolonisation: The Role of Engaged Anthropology and Academic Coaching in the Decolonisation Project in South African Higher Education. Creative Education, 12, 2831-2845. https://doi.org/10.4236/ce.2021.1212210

Received: October 13, 2021

Accepted: December 17, 2021

Published: December 20, 2021

Copyright (อ 2021 by author(s) and Scientific Research Publishing Inc. This work is licensed under the Creative Commons Attribution International License (CC BY 4.0).

http://creativecommons.org/licenses/by/4.0/ (c) (i) Open Access

\begin{abstract}
Prior to the COVID-19 pandemic, many universities were in the middle of violent student protests linked to the debate on decolonisation in Higher Education. These protests flared up again in March 2021. Since 2015, which saw the emergence of the Fees Must Fall and Rhodes Must Fall movements in South Africa, decolonisation has been on the national agenda. Unfortunately, much of the meaningful debate around decolonisation was, and continued to be right up until just before the outbreak of the pandemic, marred by violent uprisings on various campuses throughout the country. In this article, I pose the question of how Higher Education can strive towards meaningful decolonisation as a necessary step in transforming the higher education landscape. By means of a review of relevant literature, I argue that engaged anthropology, and its role in academic coaching, can make a valuable contribution to the decolonisation project. The article focuses on the significance of engaged academic anthropology, and how, through its influence on academic coaching, it can be a useful tool in promoting the decolonisation project, by minimising the violent and destructive aspects of decolonisation that have, unfortunately, become an all too familiar part of decolonisation discourse.
\end{abstract}

\section{Keywords}

Decolonisation, South African Higher Education, Engaged Anthropology, Academic Coaching

\section{Introduction}

Over the last five years, the issue of decolonisation in Higher Education Institu- 
tions (HEIs) in South Africa has been (forcefully) placed on the national agenda. Very few, if any, HEIs remain unaffected by the decolonisation debate. In March 2015, the decolonisation issue was forced onto the national political landscape, when South Africa was "engulfed in a wave of student protests" (Nyamnjoh, 2017: p. 256) which culminated in the Rhodes Must Fall movement. On 9 March 2015, University of Cape Town (UCT) student Chumani Maxwele vandalised a statue of British colonialist Cecil John Rhodes with human excrement. The statue was located on the university premises. This act catalysed further student action, which included the "occupation of university buildings, as well as on-going debates and changes at UCT and other universities across South Africa and abroad." (Murris, 2016: p. 276).

Later, in October 2015, several student protest movements mobilised behind what Hodes (2017: p. 140) called a "unity of purpose", namely free higher education. This could be seen as an extension of the Rhodes Must Fall movement, and became known as Fees Must Fall. At the heart of this movement were student protests against the high costs of university education, and the demand that all university fees be scrapped.

Since 2015, the \#RhodesMustFall and \#FeesMustFall movements have gathered momentum. This has resulted in ongoing sporadic nation-wide student protests across various university campuses in South Africa. One of the defining features of these protests, however, is the violence that seemingly accompanies the protests. Various campuses were hit by violent protests and clashes between students and law enforcement. The ongoing violence prompted the Minister of Higher Education, Science and Technology, Dr Blade Nzimande, to "strongly condemn" violent student protests. The Minister stated that violent protests were "wholly unacceptable and provides no solution to student concerns." (Department of Higher Education and Training, 2020). The Minister further called on law enforcement agencies to "act swiftly against any acts which result in violence and destruction of public and private property." (Department of Higher Education and Training, 2020, n.p.).

Just prior to the outbreak of the COVID-19 pandemic in 2020, at least two South African universities were once again hard hit by violent student protests. In January 2020, it was reported that the Mahikeng campus of North West University was "forced to close as [a] result of violent student protests." This followed an announcement by the South African Union of Students for "the national shutdown of public universities... citing complaints about fees and historical debt." (Sobuwa, 2020). Furthermore, in February 2020, the University of KwaZulu-Natal experienced "[v]iolent and chaotic scenes", as student protestors "clashed with private security guards hired by the institution." (Duma, 2020, n.p.).

While the COVID-19 pandemic had halted normal university operations, the incidents referred to above suggest that the decolonisation debate at universities is, as yet, unresolved. This article argues for an engaged anthropological approach 
as a contribution towards finding a meaningful resolution to the decolonisation question. Specifically, it argues for a combination of engaged anthropological insights and academic coaching as a practical way towards creating meaningful progress towards decolonisation. With reference to relevant literature, I outline the possible role that engaged anthropology and academic coaching could play in promoting constructive and meaningful options for discussion and engagement that move beyond violence and destruction.

\section{The Decolonisation of Higher Education: A General Overview}

Within the last five years, the notion of decolonisation in Higher Education has sparked debate on a global scale. For example, Dar, Desai and Nwonka (2020) argued that, in the UK, while students have been calling for the decolonisation of university curricula for years, very few UK universities have made "meaningful changes" (see also Batty, 2020). Furthermore, during the height of the \#RhodesMustFall and \#FeesMustFall movements in South Africa during 2015 and 2016, in the US, "a decolonisation movement [was] beginning to take root in New York universities.” (Pather, 2016). And, finally, in Perth, Australia, “College students voted to 'decolonise the curriculum' to encourage more diverse reading lists in the classroom." (Chalmers, 2021).

The above examples illustrate that the decolonisation of Higher Education debate is not only an issue of national importance, but it is one of global importance. The local events of 2015 and 2016 that culminated in the Rhodes Must Fall and Fees Must Fall movements sparked a global drive towards decolonising Higher Education. For the last few years this debate has continued, and while the Covid-19 pandemic disrupted higher education activities on a global scale, the decolonisation question has not abated.

\section{Decolonisation and the Structure of Higher Education in South Africa}

In the South African context, the prickly and, as yet, unresolved, issue of decolonising Higher Education recently manifested in the form of nationwide student protests. In the most recent protests, two HEIs in the Eastern Cape Province were forced to suspend their academic activities. According to Moya (2021), Walter Sisulu University and Nelson Mandela University were forced to suspend activities due to students "protesting over a range of issues including NSFAS allowance, admissions and registration-related matters". Earlier in 2021, student protests rocked Wits University in Gauteng Province, and resulted in the death of a student allegedly by police responding to the protest action (Rakhetsi, 2021). These are a few examples of the ongoing conflicts between students and HEIs regarding structural and institutional cultural issues related to access and funding.

Even a cursory analysis of the student protests reveals that there are certain 
commonalities that characterise the protests. Almost all of them are a reaction to the current structure of Higher Education in South Africa. They also symbolise and manifest the call for decolonising this same structure. The common reasons often cited as the cause of student protests, namely funding and the scrapping of historical debt, access and free education, all point to a structure that disadvantages a large proportion of South African students. While these issues have been problematic for some time, as evidenced by the protests occurring since 2015 already, they have been exacerbated by the COVID-19 pandemic. It remains to be seen how, and to what extent, the environment created by the pandemic will impact on transformation and decolonisation within the Higher Education structure, especially as HEIs face contradictory internal and external pressures.

\section{Defining Engaged Anthropology}

Among many anthropological scholars, there is still wide-ranging debate about the role of anthropology in the decolonisation project, both within the discipline itself, and in the wider global and local society. For example, Pels (2018: p. 71) argues that "Anthropology should never be fully decolonized." He cites various reasons, including that "we cannot escape the epistemological conditions created by a dominant 'Europe'..." (Pels, 2018: p. 75). However, by contrast, Thomas (2018: p. 393) refers to the "decolonizing generation" in anthropology, who "sought to transform anthropological epistemologies, methodologies, pedagogical practices, and forms of public engagement in order to generate processes of... accountability..." (see also McGranahan and Rizvi, 2016), both within the discipline, and within the academic institutions in which anthropologists teach and study.

It is within this context that the notion of an engaged anthropology can be located. Known by various synonyms such as public anthropology, applied anthropology, activist anthropology, and others, engaged anthropology represents that part of anthropology most responsive to the decolonisation question. It should be noted at the outset that there is no uniformity about what engaged anthropology is, as there are differences of opinion about what constitutes engagement (Lamphere, 2004). However, there is general consensus on the historical processes and trajectories that led the discipline to its current emphasis on engagement.

Briefly, the historical development of anthropology as a discipline, particularly in the shift from British colonial Social Anthropology to American postcolonial Cultural Anthropology, illustrates the gradual emergence of engaged anthropology as a response to the discipline's role in creating the social and cultural problems encountered by many societies in developing countries. Various scholars, including Lamphere (2004) and Low and Merry (2010), have outlined the development of engaged anthropology as a response to the wider global and local social dynamics that had a direct and indirect impact on the increasingly public role of anthropology, specifically in addressing pressing social and cultural concerns in society. These scholars refer, for example, to the growing critical stance 
of American anthropologists on issues of marginalisation and exclusion, human rights, racism and other diversity related issues borne from social movements such as the Civil Rights movement in the 1960s and 1970s. Specifically, they also refer to the increasing role of anthropologists in educating the wider public on these issues, utilising anthropological ideas, knowledge and insights to educate and inform. It is this form of engagement that concerns us in this discussion, and which informs my definition or understanding of engaged anthropology.

Within the context of the current discussion, engaged anthropology can be defined as the use of anthropological knowledge, insights and/or methods in public education. In this context, public education refers to both formal and informal education. It is primarily concerned with the contribution of anthropology to public education on decolonisation and related issues. The purpose of this form of engaged anthropology is to use the discipline to challenge and engage the wider society on contemporary issues of social concern, in this case, the decolonisation of universities. Questions such as: how do we understand decolonisation?; or what role could anthropology play in the decolonisation debate?; or how could anthropology play a supportive or facilitative role in aiding the constructive and positive resolution of the decolonisation question?; these are all questions that engaged anthropology, defined as outlined above, aims to address.

Inasmuch as engaged anthropology, as defined here, is concerned with public education on decolonisation, its application is within the context of Higher Education, specifically in universities. It can be argued that the very argument for the use of engaged anthropology in transformation is inextricably linked to the decolonisation agenda in universities, and has been since at least the 1990s. In his Presidential Address to the $94^{\text {th }}$ Annual Meeting of the American Anthropological Association in 1995, James Peacock argued that the survival of anthropology in universities lay in its engagement beyond the academic. This engagement should include "transforming academia and breaking out of the stratification of anthropology itself." (Low and Merry, 2010: p. 207; see also Peacock, 1997). This view of engaged anthropology frames the current discussion on the contribution of the discipline to decolonisation in South African higher education.

\section{Advantages and Disadvantages of Engaged Anthropology in the Higher Education Decolonisation Project}

It is necessary to take a critical look at the value of engaged anthropology for meaningful decolonisation in South African higher education. In this context, critical refers to outlining some advantages as well as disadvantages of the engaged application of the discipline to decolonisation and higher education.

In the US, anthropology had made both a theoretical and methodological contribution to studies on higher education since the 1990s (Shumar, 2004: p. 30). For example, Holland and Eisenhart's (1990) work demonstrated the anthropological tradition of defamiliarising the familiar, in their application of basic social theory to understanding undergraduate culture in the US. According to 
Shumar (2004: p. 31), "The advantage [of] this approach is that it allows us to see commonplace activities in a new light..." This resonates strongly with the notion of "stepping in and stepping out" of cultures, as outlined by Sunstein and Chiseri-Strater (2012). In anthropological terms, this refers to the ability to become both an insider-participant as well as an outsider-observer of a particular cultural context. Both perspectives are crucial to develop a holistic and more accurate understanding of the cultural context in question. Within the context of decolonisation in higher education, this approach is advantageous in two ways. First, it encourages a critical view of university culture, in terms of questioning what we do, how we do it, and why. Second, it encourages academics to "step out" of their familiar roles as academics, and "step into" the unfamiliar experiences of students and how they perceive the university context. Third, by looking at decolonisation and higher education as an outsider, it allows academics to identify strategies of how to address the weaknesses in the higher education system to promote meaningful decolonisation.

Another area where engaged anthropology can be useful is in understanding the relationship between the "commodification of education" (Shumar, 2004: p. 36), or, as it is also known, the "marketization of higher education" (Canaan, 2002) and decolonisation. As alluded to earlier in the discussion, the emergence of the call for decolonising higher education in South Africa developed concurrently with the call for the eradication of university fees and student debt. Hence, the question of the commodification of higher education cannot be separated from the decolonisation question. Shumar (2004: p. 34) outlines the value of the anthropological perspective in this context, by arguing that it "looks at the relationship between global forces and how they impact the national political economy and then at the effect on local universities..." For the engaged anthropologist, this speaks to issues of affordability, exclusion/inclusion, access to the right to education, class differences, power dynamics and various other related issues already familiar to anthropologists doing engaged work. In South African higher education, all of these issues are paramount in the decolonisation debate.

Inasmuch as the above illustrates some of the advantages that anthropological engagement could have in addressing decolonisation in South African higher education, it is necessary to also take note of some potential disadvantages of an engaged approach. Specifically within the context of anthropological engagement in higher education, there are several barriers that could potentially hamper meaningful engagement.

Low and Merry (2010) describe various barriers to meaningful anthropological engagement, but I will limit the discussion to two of these barriers in particular, that are relevant to this discussion. One barrier is that anthropologists often silence themselves out of fear of appearing imperialistic or colonialist, and therefore may avoid criticising institutions, organisations or governments other than their own. This barrier has its origins in the so-called "guilt complex" of postcolonial anthropologists, due to the "historical collusion of anthropology and 
colonialism" (Low and Merry, 2010: p. 213). In the context of decolonisation, anthropologists' preoccupation with not appearing colonialist can hamper their engagement efforts, particularly when confronted with destructive behaviours in universities, under the guise of decolonising institutions.

A second barrier to meaningful anthropological engagement in the university context is anthropology's emphasis on the specificity of context, and, consequently, its resistance to universalising discourses. According to Low and Merry (2010: p. 213), this focus on particularity of context "puts anthropology at odds with several universalizing discourses of importance to the field." At the heart of this dilemma is the protection of difference. Anthropologists are highly sensitive to differences in perception, behaviour and context, and how these differences can shape institutions and organisations. In higher education institutions, the decolonisation debate is fraught with different perspectives and views on how it should be approached. This could potentially put anthropologists at odds with the dominant universalising views of decolonisation, and how it should be implemented, especially if these views seek to impose a one-sided view of decolonisation.

While we can acknowledge that engaged anthropology is not without its flaws, its contribution to the decolonisation issue in higher education institutions cannot be underestimated. The nature of the discipline, as well as the advantages of an engaged anthropological approach, as outlined earlier, makes anthropology indispensable in the quest for meaningful decolonisation. However, the success of engaged anthropology in its contribution to meaningful decolonisation in South African higher education institutions is dependent on its interaction with another indispensable tool, namely academic coaching.

\section{Understanding Academic Coaching and Its Relevance to Decolonisation in Higher Education Institutions}

Academic coaching, particularly in higher education, is a relatively new field, both internationally, and within the South African context. According to Robinson (2015: p. 1), the "academic success coach" is a new role that emerged in higher education over the last two decades. Robinson (2015), as well as Bettinger and Baker (2011), agree that academic success coaching emerged in higher education in the 2000s, when a company, InsideTrack, provided coaching assistance to higher education institutions in the US seeking to improve their student retention rates. This subsequently led to "hundreds of institutions creat[ing] their own in-house coaching services, and the number of coaching programs nationally has proliferated since that time." (Robinson, 2015: p. 1). Robinson (2015) conducted a national study on coaching programmes in US higher education institutions. Part of her survey included identifying the main reasons why institutions created coaching programmes in the first place. According to Robinson's (2015) survey results, there were two main reasons why academic institutions created coaching programmes: 
1) Increasing retention (55.6\%)

2) Assisting academically deficient students (37.5\%)

Based on this study, there is evidence to suggest that institutions are increasingly turning to academic coaching "as a method for increasing retention and graduation rates” (Warren 2019: pp. 2, 7; see also Capstick, Harrell-Williams, Cockrum and West, 2019; Deiorio, Carney, Kahl, Bonura and Juve, 2016). So while academic coaching has been an established practice in the US over the last twenty or so years, what about elsewhere in the world?

At the Ort Braude College of Engineering in Karmiel, Israel, Ben-Yehuda (2015) conducted a study on the success of a personal-academic coaching programme to assist engineering students. Twenty-four lecturers were trained as personalacademic coaches for the programme. Primarily, the coaching programme focused on self-management, learning management, time and tasks management, coping with stressful situations and overload, and academic learning (Ben-Yehuda, 2015: p. 324).

Hakro and Mathew (2020) conducted a case study on a Cognitive Coaching programme in a higher education institution in Oman. They specifically investigated whether the programme made any difference to the attitudes and behaviour of staff members holding leadership positions in academic, administrative and professional services departments. They argue that universities and higher education institutions are "increasingly recognizing the value of coaching for professional and organizational development." (Hakro and Mathew, 2020: p. 307). Their findings suggested that coaching can be effective in facilitating personal and professional development, as well as contributing to the achievement of organisational goals.

The above examples illustrate that there is increasing recognition of the role of academic coaching in higher education institutions internationally. What is the state of academic coaching in the South African context?

According to Le Roux (2018), in the South African context, there is limited research on the experiences of postgraduate students trying to navigate three key overlapping roles including work, personal life and studies. Even less is known about the impact of coaching as a supportive intervention for postgraduate students. Le Roux (2018) conducted a case study on coaching as a support mechanism for postgraduate students. She selected ten university postgraduate students registered in Business Management. They were invited to participate in a fivemonth coaching programme. The study found, among other things, that there is a certain level of incompatibility between study, social and/or personal life and work, if not supported by some or other kind of intervention. Coaching, as a supportive intervention, has value in providing a space for a dyadic conversation that encourages self-reflection and problem-solving.

Le Roux (2018) also outlines the practical implications of having a coaching intervention for universities and other organisations with employees pursuing further studies. She argued that for universities, it is vital to provide coaching support to postgraduate students to reduce personal life stressors and conflicts. 
Supervisors cannot fulfil this role because, as Le Roux (2018) argues further, they are neither equipped, nor comfortable, with addressing such issues with their students. It can also be argued that there is an ethical issue as well, regarding the boundaries in the supervisor-student relationship. Supervisors would provide much needed assistance predominantly for academic success, while coaching would focus on socio-emotional coping strategies, to provide a holistic approach to academic study/work performance and success.

The previous point, to a large extent, provides a broad definition of what academic coaching is. It can be understood as a supportive mechanism or tool, designed to provide holistic support to students, and/or academic staff (including academic leadership), with the aim to enhance academic performance and success. While broad, this definition can be applied to specific key areas in academic performance where academic coaching may be useful, and depending on the specific needs of the coachee.

The above definition focuses to a large extent on a broad understanding of academic success. However, if academic coaching is applied to the context of decolonisation, a wider understanding of academic success is required. There is a need to move beyond traditional understandings of academic success to include other dimensions that impact on that success, including academic management, leadership, financial aspects, organisational culture and relationships. In other words, academic coaching should include everything that could potentially contribute to the success of the academic institution as a whole, and not just individually. Most understandings of coaching focus on a one-on-one coaching relationship between the coach and individual coachee. This discussion challenges this notion, and argues that, within the broader context of decolonisation, and the potential contribution that academic coaching can make in this regard, academic coaching should include the institution as a whole, and not just individuals. In other words, I understand academic coaching in terms of its role in contributing to the success of the academic institution as a whole.

The decolonisation debate impacts on virtually every facet of the higher education institution, and directly affects both students and staff (including the academic institutional leadership and management). Academic coaching, as an intervention and support mechanism, would thus be a useful tool in assisting both staff and students in navigating the challenging terrain of decolonisation. In combination with insights and perspectives from engaged anthropology, coaching could potentially be the one thing that can not only ensure progress in the decolonisation debate, but also practical and actionable solutions.

\section{Combining Engaged Anthropology and Coaching for Decolonisation}

The one thing that links engaged anthropology, as understood in this discussion, and coaching is that both are concerned with transformation. Engaged anthropology has been concerned with the dynamics of change in cultures and societies 
at least since the 1960s, and this concern continues into the present. Coaching is concerned with the transformation of an individual from where they are to where they would like to be.

Within the higher education context, decolonisation is also about transformation. Since the mid-1990s, with the publication of the National Commission on Higher Education's report (1996) on transforming the sector, there have been various policy and other interventions designed to effect transformation across the higher education landscape. One of the key aspects of this transformation agenda was access to higher education. However, this has been an ongoing issue, culminating in the nationwide student protests of the Rhodes Must Fall and Fees Must Fall movements. As yet, the issue of access remains unresolved, as evidenced by the most recent spate of student protests in March 2021, which led to a national shutdown of universities across South Africa (eNCA News, 2021; Nicolson, Egwu and Payne, 2021; Charles, 2021).

The most effective way to advance decolonisation in higher education, while minimising the disruption, violence and other unconstructive consequences that have become the norm, is to combine engaged anthropology and academic coaching. By utilising the insights and techniques of both, a more viable, sustainable and constructive approach to decolonisation can ensue. The strength of combining engaged anthropology and coaching emanates from the similarities between these approaches. As illustrated earlier, both engaged anthropology and coaching are sensitive to the context in which transformation needs to take place. Furthermore, both are concerned with meaningful transformation, emphasising positive growth. Both also emphasise a partnership or mutually co-operative winwin relationship as fundamental to success, rather than a top-down approach, where, inevitably, there is a perceived winner and a perceived loser.

By combining engaged anthropology and coaching, five key areas can be identified for engagement and coaching. These five areas are:

1) Clarity of vision and direction.

2) Relevant skills that are needed to facilitate the transformation/decolonisation process.

3) Optimising the higher education environment for success.

4) Overcoming mindset and emotional blocks that can sabotage the process.

5) Developing a strategic action plan that is sustainable and implementable.

Each of the above focus areas is necessary to address, as they all are integrated and inter-connected. If the higher education institution is viewed as a cultural system, then the above aspects make up its constituent parts. Addressing any one of these will have implications for the other aspects, and ultimately impact on the entire system. Hence, a comprehensive programme, encompassing each of these aspects, would be required to effect meaningful transformation at all levels of the institutional culture. While the above five considerations are admittedly broad, the unique context of the individual institution would determine the prioritisation of these aspects, and how each is to be addressed. 


\section{Implications for South African Higher Education}

The preceding discussion has outlined an argument that engaged anthropology and coaching could play significant roles in advancing meaningful decolonisation in South African higher education. But what could be some of the more specific implications of using this approach?

\section{A shared, clearer and more defined vision of decolonisation}

The current conflicts between students and HEI institutional leadership stem from a lack of a shared vision of what decolonisation should look like. This suggests that for any meaningful progress to be made, there needs to be some common understanding reached about what the vision of decolonisation should be. A coaching conversation aimed at clarifying this vision would make a significant difference is creating common ground, and a starting point for a shared vision.

\section{A changing institutional culture}

A need to change institutional culture lies at the heart of the calls for decolonisation. The concerns around historical student debt, fees, exclusion, institutional leadership and governance, and even curricula, all have to do with transformation of the HEI institutional culture. As discussed earlier, an engaged anthropological approach focuses on the specific cultural context under consideration. The insights gleaned could assist in conversations about how the institutional culture could (or should) change in order to facilitate meaningful decolonisation.

\section{Leadership in successful HEI decolonisation}

Successful implementation of institutional cultural change, and, by implication, decolonising HEI's institutional culture, would enable South African HEIs to play a leadership role in charting the best possible strategy to facilitate decolonisation in higher education. South African HEIs that demonstrate successful institutional transformation would serve as best practice examples to HEIs globally, especially those still struggling with transformation and decolonisation issues.

\section{Enhanced communication and dialogue between stakeholders}

As discussed earlier, one of the key (and unfortunate) features the decolonisation debate is the violence and destruction of property. In most cases, these are the result of a breakdown in communication and dialogue between HEI leadership and student bodies. Furthermore, the fact that this seems to happen annually suggests that there is indeed a need for a more constructive and meaningful way to resolve the impasse. Consequently, the suggested approach could serve to minimise (if not eliminate) the negative consequences of poor communication between the relevant stakeholders. This could, in turn, minimise the disruption, stress and violence that have become all too common in student protests against the lack of institutional transformation.

An optimised environment for student and institutional success

Few would argue that one of the most vital responsibilities of institutions of 
higher learning is to produce graduates who can make a significant contribution to the development of society. In order for this crucial function to be carried out, the HEI environment should ideally be optimised for success. The current environment characterised by sporadic student protests, violence, disruption of the academic calendar, uncertainty and anxiety (for both students and staff), do little to foster an environment conducive to academic success. Hence, the suggested approach of using coaching and engaged anthropology, could encourage stakeholders to engage on how the environment can be optimised for success. An environment where students feel that they are given the best possible chance to succeed, and where the institution itself can continue to grow and develop, is the ideal that every HEI should strive for.

\section{Conclusion}

There is little doubt that decolonisation is arguably the most significant challenge facing higher education institutions in South Africa. It is significant because it impacts on virtually every aspect of higher education institutional culture, including governance and management; finances; policies; selection and appointments; teaching, learning and research; and student acceptance and registration. Indeed, the twin issues of student fees and free tertiary education remain the most common manifestations of the decolonisation debate, as reflected in the ongoing student protests about fees and free education.

Regardless of the need to engage and debate the decolonisation issue, a distinction must be made between unconstructive attempts to decolonise versus meaningful decolonisation. Unfortunately, thus far the decolonisation question has been mired by violence, destruction of property, disruption of the academic programme and even intimidation, all of which are unconstructive. This discussion put forth the argument that firstly, higher education institutions in their entirety (meaning management, governance, staff and students) need to strive for meaningful decolonisation. Second, it was argued that one way in which this meaningful decolonisation can be achieved is by combining engaged anthropological principles and the tools and techniques of academic coaching. Both are relevant as they have certain strengths that could play a significant role in taking the debate forward in a constructive manner. Institutional leadership, academic and non-academic staff, as well as students would all benefit from an engaged, coaching partnership, designed to encourage positive approaches to decolonisation, self-reflection, and solutions that would benefit the higher educational system as a whole, rather than one group seemingly benefitting at the expense of the other.

The coaching process is not an easy one. It requires introspection and a critical, honest self-reflection and willingness to acknowledge and address negative attitudes and behaviours that hamper meaningful progress. Without these, no constructive, viable and sustainable solutions can be found, meaning that the very same problems that higher education institutions currently experience are 
likely to continue, while the decolonisation question remains unresolved.

In response to the latest wave of student protests that led to a national shutdown of tertiary institutions in March 2021, Minister of Higher Education and Training, Blade Nzimande, compared the now annual student protests to a soap opera, basically articulating that at the start of every academic year there is instability at institutions. Surely the time has come to change this, and to take the process of decolonisation forward. But, it is imperative that it be done in the right way, so that we ensure that decolonisation is both meaningful and positive for all stakeholders in higher education.

\section{Conflicts of Interest}

The author declares no conflicts of interest regarding the publication of this paper.

\section{References}

Batty, D. (2020, June 11). Only a Fifth of UK Universities Say They Are "Decolonising" Curriculum. The Guardian.

https://www.theguardian.com/us-news/2020/jun/11/only-fifth-of-uk-universities-havesaid-they-will-decolonise-curriculum

Ben-Yehuda, M. (2015). The Route to Success: Personal-Academic Coaching Program. Procedia: Social and Behavioral Sciences, 209, 323-328. https://doi.org/10.1016/j.sbspro.2015.11.242

Bettinger, E. P., \& Baker, R. (2011). The Effects of Student Coaching in College: An Evaluation of a Randomized Experiment in Student Mentoring. Working Paper No. 16881, National Bureau of Economic Research. https://doi.org/10.3386/w16881 http://www.nber.org/papers/w16881.pdf

Canaan, J. (2002). Theorizing Pedagogic Practices in the Contexts of Marketization and of September 11, 2001, and Its Aftermath. Anthropology and Education Quarterly, 33, 368-382. https://doi.org/10.1525/aeq.2002.33.3.368

Capstick, M. K., Harrell-Williams, L. M., Cockrum, C. D., \& West, S. L. (2019). Exploring the Effectiveness of Academic Coaching for Academically at-Risk College Students. Innovative Higher Education, 44, 219-231. https://doi.org/10.1007/s10755-019-9459-1

Chalmers, R. (2021, February 2). Vote to "Decolonise Curriculum" at UHI Colleges Is Passed. Daily Record.

https://www.dailyrecord.co.uk/news/local-news/vote-decolonise-curriculum-uhi-colleg es-23427698

Charles, M. (2021, March 15). More Student Protests Expected on Tuesday. News24. https://www.news24.com/news24/SouthAfrica/News/more-student-protests-expectedon-tuesday-here-is-a-list-of-students-demands-20210315

Dar, S., Desai, M., \& Nwonka, C. (2020, June 17). "Students Want to Confront It”: Academics on How to Decolonise the University. The Guardian.

https://www.theguardian.com/education/2020/jun/17/students-want-to-confront-it-ac ademics-on-how-to-decolonise-the-university

Deiorio, N. M., Carney, P. A., Kahl, L. E., Bonura, E. M., \& Juve, A. M. (2016). Coaching: A New Model for Academic and Career Achievement. Medical Education Online, 21, Article No. 33480. https://doi.org/10.3402/meo.v21.33480 
Department of Higher Education and Training (2020, January 29). Minister Blade Nzimande Condemns Violent Student Protests. Government of South Africa. https://www.gov.za/speeches/minister-nzimande-condemns-29-jan-2020-0000

Duma, N. (2020, February 19). UKZN Protest Turns Violent as Students, Security Clash at Westville campus. EWN Eye Witness News. https://ewn.co.za/2020/02/19/ukzn-protest-turns-violent-as-students-security-clash-atwestville-campus

eNCA News (2021, March 22). Student Protests Set to Continue. https://www.enca.com/news/watch-student-protests-set-continue

Hakro, A. N., \& Mathew, P. (2020). Coaching and Mentoring in Higher Education Institutions: A Case study in Oman. International Journal of Mentoring and Coaching in Education, 9, 307-322. https://doi.org/10.1108/IJMCE-05-2019-0060

Hodes, R. (2017). Questioning “Fees Must Fall”. African Affairs, 116, 140-150. https://doi.org/10.1093/afraf/adw072

Holland, D. C., \& Eisenhart, M. A. (1990). Educated in Romance: Women, Achievement, and College Culture. University of Chicago Press.

https://doi.org/10.7208/chicago/9780226218496.001.0001

Lamphere, L. (2004). The Convergence of Applied, Practicing and Public Anthropology in the 21st Century. Human Organization, 63, 431-443. https://doi.org/10.17730/humo.63.4.y14pe24v7ekyklyp

Le Roux, I. (2018). Coaching as Support for Postgraduate Students: A Case Study. South African Journal of Human Resource Management, 16, Article No. a939. https://doi.org/10.4102/sajhrm.v16i0.939

Low, S. M., \& Merry, S. E. (2010). Engaged Anthropology: Diversity and Dilemmas. Current Anthropology, 51, S203-S226. https://doi.org/10.1086/653837

McGranahan, C. and Rizvi, U.Z. (2016, April 19). Decolonizing Anthropology. Savage Minds. https://savageminds.org/2016/04/19/decolonizing-anthropology/

Moya, Z. (2021, April 14). Academic Activities Remain Suspended at Two E Cape Universities as Students Protest over NSFAS. SABC News.

https://www.sabcnews.com/sabcnews/academic-activities-remain-suspended-at-two-ecape-universities-as-students-protest-over-nsfas/

Murris, K. (2016). \#Rhodesmustfall: A Posthumanist Orientation to Decolonising Higher Education Institutions. South African Journal of Higher Education, 30, 274-294. https://doi.org/10.20853/30-3-653

National Commission on Higher Education (1996). A Framework for Transformation. Pretoria.

Nicolson, G., Egwu, S., \& Payne, S. (2021, March 20). Protest, Politics, Education: Students' Ongoing Battle for Access. Daily Maverick. https://www.dailymaverick.co.za/article/2021-03-20-protest-politics-education-student s-ongoing-battle-for-access/

Nyamnjoh, A. (2017). The Phenomenology of Rhodes Must Fall: Student activism and the experience of alienation at the University of Cape Town. Strategic Review for Southern Africa, 39, 256-277. https://doi.org/10.35293/srsa.v39i1.330

Pather, R. (2016, October 18). Students in New York Rise up in Solidarity with \#FeesMustFall. Mail \& Guardian.

https://mg.co.za/article/2016-10-18-students-in-new-york-rise-up-in-solidarity-with-fe esmustfall/

Peacock, J. L. (1997). The Future of Anthropology. American Anthropologist, 99, 9-17. 
https://doi.org/10.1525/aa.1997.99.1.9

Pels, P. (2018). Anthropology Should Never Be Fully Decolonized... Etnofoor, 30, 71-76.

Rakhetsi, A. (2021, March 11). South Africa's Wits University Students Are Protesting rising Debt and Education Costs. Global Citizen.

https://www.globalcitizen.org/en/content/wits-students-protest-fees-must-fall-south-af rical

Robinson, C. E. (2015). Academic/Success Coaching: A Description of an Emerging Field in Higher Education. $\mathrm{PhD}$ thesis, University of South Carolina.

Shumar, W. (2004). Making Strangers at Home: Anthropologists Studying Higher Education. The Journal of Higher Education, 75, 23-41.

https://doi.org/10.1080/00221546.2004.11778894

Sobuwa, Y. (2020, January 29). NWU Campus Closed as Violent Protests Hit Varsities. Sowetan Live.

https://www.sowetanlive.co.za/news/south-africa/2020-01-29-nwu-campus-closed-as-v iolent-protests-hit-varsities/

Sunstein, B. S., \& Chiseri-Strater, E. (2012). Field Working: Reading and Writing Research (4th ed.). Bedford/St Martin's.

Thomas, D. A. (2018). Decolonizing Disciplines. American Anthropologist, 120, 393-397. https://doi.org/10.1111/aman.13102

Warren, D. J. (2019). Academic Coaching in Higher Education: Exploring the Experiences of Academic Coaches. Unpublished D. Ed Thesis, University of Memphis. 